\title{
COMPARATIVE CHARACTERISTIC OF THE MECHANICAL STRENGTH OF COMPLETE DENTURES PERFORMED BY STANDARD TECHNIQUE AND IVOCAP TECHNOLOGY
}

\author{
Metodi Abadzhiev \\ Prosthodontic Department, Faculty of Dental Medicine, \\ Medical University - Varna
}

\section{SUMMARY:}

The record of complete denture performing is almost the same as hasn't undergone any changes since the introduction of acrylics by Kulzer in 1935. The air, included into the dentures, decreases their mechanical strength. This problem is solved by inventing the IVOCAP technology by IVOCLAR VIVADENT.

Key words: IVOCAP technology, MDI

\section{PURPOSE:}

Comparison of the mechanical strength indices of complete dentures, made by standard technique and IVOCAP technology.

\section{INTRODUCTION:}

Frequently encountered clinical situations in which it is necessary to use the roots of natural teeth or implants for retention purposes prostheses. (Fig. 1.) The rezilents of the mucousis, on the one hand and the rigidity of the roots or implants on the other, lead to the occurrence of structural balance. The long period in balance leads to premature fatigue of the material and ultimately to fractured. In such cases, recourse to casting removable prosthesis. This makes the treatment expensive, and adding another alloy, increases the risk of corrosion. With the emergence of Ivokap technology the total strength of the prostheses, has increased which makes it unnecessarily reinforced by casting grill. Ivokap nature of technology is that it is uses to special locking cuvette (fig. 2., fig. 3.), to withstand high pressure automatic mixing of plastics (fig. 4.) and ensures the tank with plastic nonpolimerizat plastic that fill with 6 bar pressure throughout the polimerizations cycle.

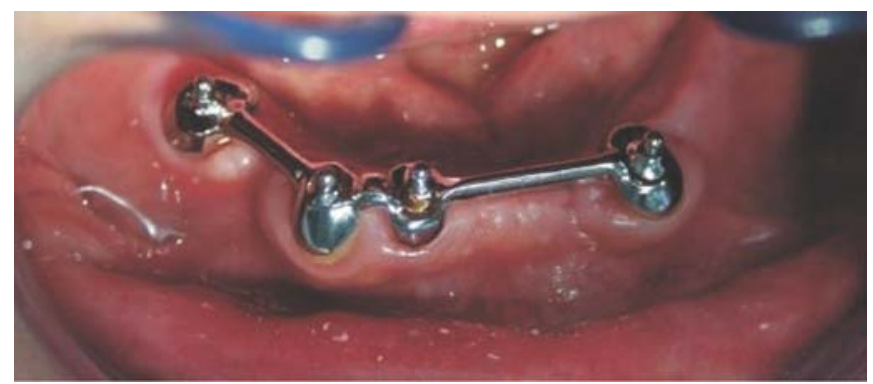

Fig. 1. Over dentures clinical case

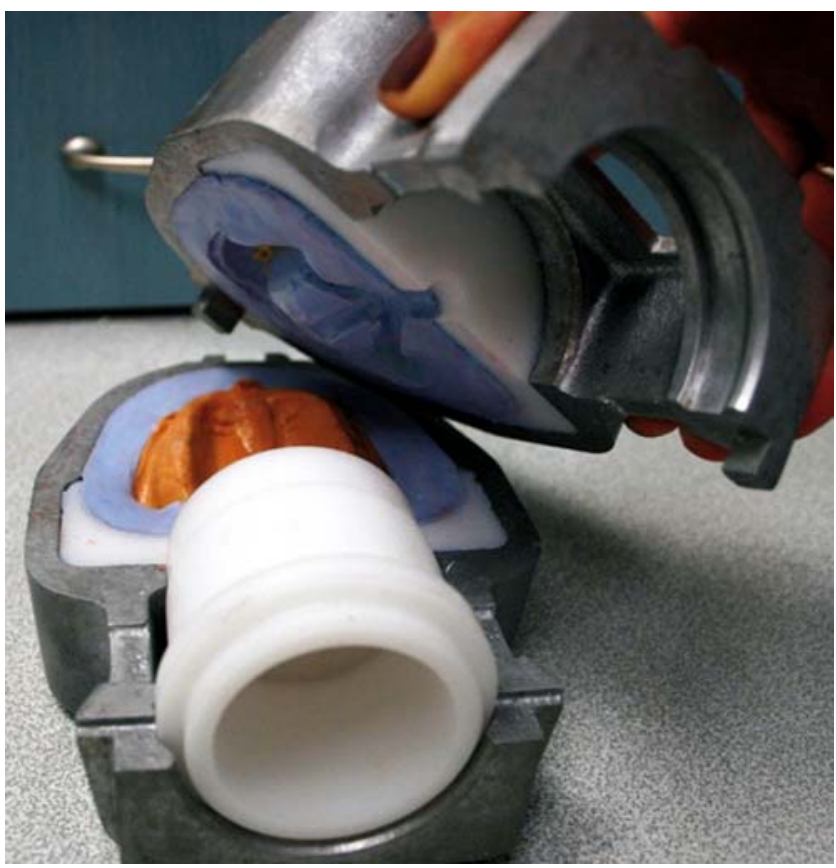

Fig. 2. The special polymerization box before closing 


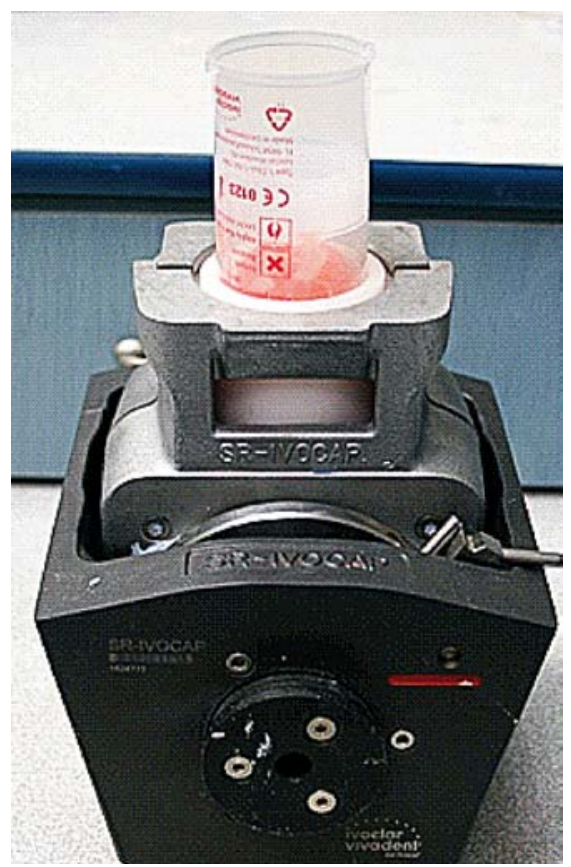

Fig. 3. The polymerisation box locked in the pressure resistant unit

\section{METHODS AND MATERIALS:}

40 acrylic blocks with dimensions $10 \mathrm{~mm} / 30 \mathrm{~mm} / 7 \mathrm{~mm}$. 20 blocks are worked out by standard technique and the rest 20 blocks - by IVOCAP technology. Measuring device for the mechanical strength indices ZDM 2,5/01, speed $4 \mathrm{sm} /$ $\min$.

32 patients with 36 lower complete dentures and overdentures worked out by standard technique and 17 patients with 22 complete dentures and overdentures by

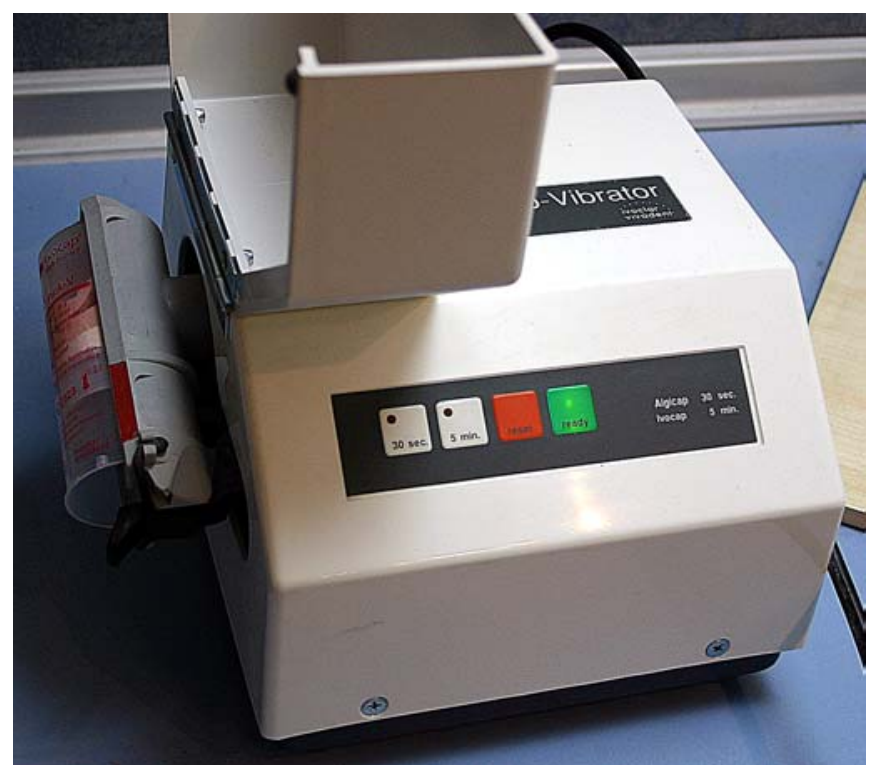

Fig. 4. The mixing unit

IVOCAP technology.

The half, - about 10 bloks of each groups were made older with the method of temperature shock.

\section{RESULTS:}

1. Laboratory - this experiment clearly shows the higher/better mechanical strength indices of the blocks, worked out by IVOCAP technology.

Table 1. The results of experimental laboratory study

\begin{tabular}{|lr|r|r|r|r|}
\hline \multirow{2}{*}{} & \multicolumn{2}{|c|}{ Ivocap } & \multicolumn{2}{c|}{ standard technique } \\
\cline { 3 - 6 } & & New & Older-looking & New & \multicolumn{1}{c|}{ Older-looking } \\
\hline Average & 1468,18 & 1187,31 & 985,49 & 915,482 \\
\hline Standard middle error & 91,182 & 87,13 & 30,5381 & 9,767 \\
\hline Standard deviation & 294,5 & 253,9 & 96,4531 & 30,919 \\
\hline \multirow{2}{*}{ Confidence interval } & from & 1248,54 & 1025,91 & 915,541 & 897,57 \\
\cline { 2 - 6 } & to & 1667,61 & 1371,87 & 1053,54 & 941,764 \\
\hline
\end{tabular}

2. Clinical - standard technique -4 broken dentures by the 3 rd wear and 2 by the 4 th.

- IVOCAP - no broken dentures.

\section{DISCUSSION:}

The tank with unpolimerized plastic, supercharged to 6 Bar during the whole polimerization cycle, (fir. 5.) refuses working out dentures free of microair pores. This gives the great mechanical strength of the IVOCAP dentures

We can say that the IVOCAP dentures cast in a mould. (fig. 6.) 


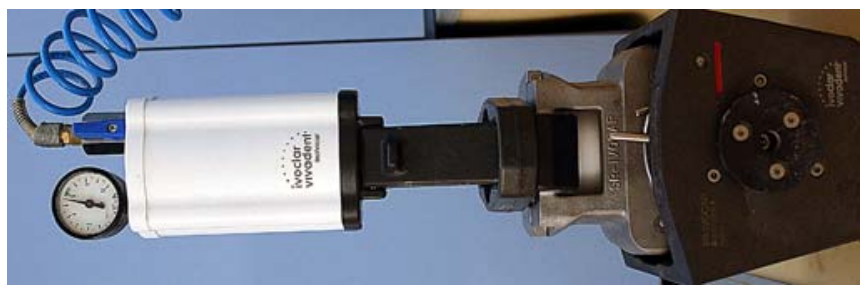

Fig. 5. The IVOCAP prosthesis during the polymerization

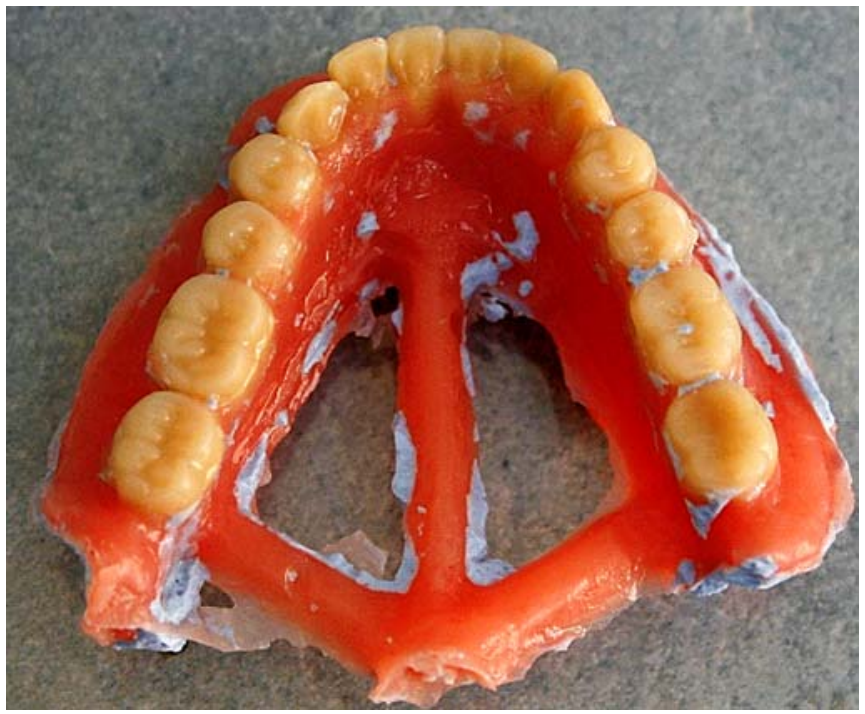

Fig. 6. The fabricated prosthesis

\section{CONCLUSION:}

It is recommended to work out complete dentures by IVOCAP technology, due to their better mechanical strength indices.They are especially suitable by pronounced maxillary suture, all cases of overdentures and by implant supported removable prosthesis.

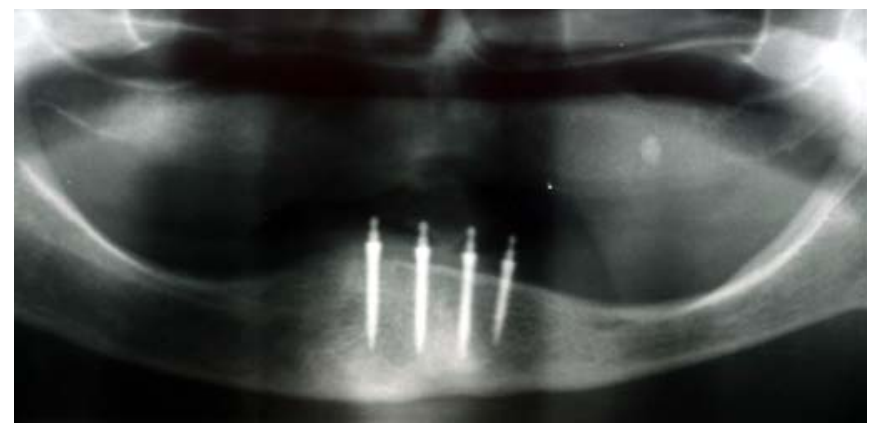

Fig. 7. Orthopanthomografy with 4 MDI

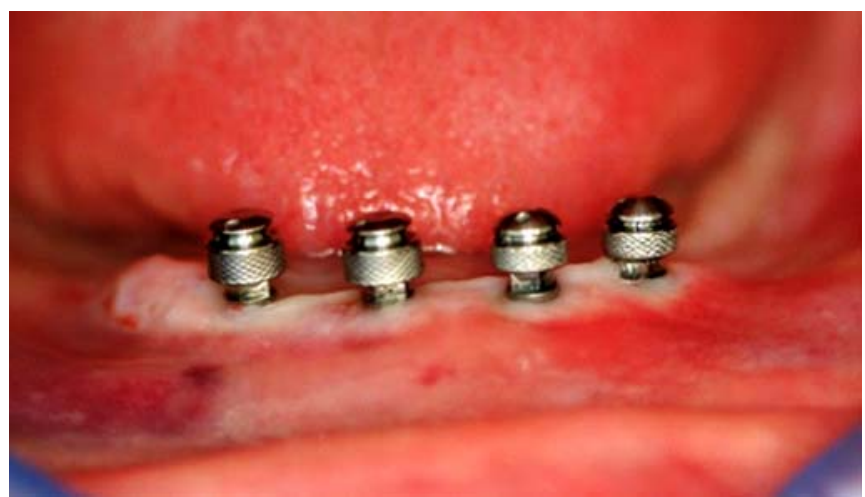

Fig. 8. The clinical situation of the same case

\section{REFERENCES:}

1. Comparison of mechanical strength of palatal denture bases made from various plastic materials.Hedzelek W, Gajdus P.Int J Prosthodont. 2006 Mar-Apr;19(2):193-4.

2. Comparison of the dimensional accuracy of injection-molded denture base materials to that of conventional pressurepack acrylic resin. Parvizi A, Lindquist T, Schneider R, Williamson D, Boyer D, Dawson DV. J Prosthodont. 2004 Jun;

\section{3(2): 83-9.}

3. Comparison of fracture tests of denture base materials. Zappini G, Kammann A, Wachter W.J Prosthet Dent. 2003 Dec;90(6):578-85.

4. Comparison of the fracture resistance of six denture base acrylic resins. Uzun G, Hersek N. J Biomater Appl. 2002 Jul; 17(1):19-29.

5. Accuracy of the acrylic resin pattern for the implant-retained prosthesis. Ness EM, Nicholls JI, Rubenstein JE, Smith DE. Int J Prosthodont. 1992 Nov-Dec; 5(6): $542-9$

6. [Finishing procedures with Ivocap system] Caesar H.H. Dent Labor (Munch). 1991 May;39(5):681-6, 688-91, 694

7. [Accuracy of SR-IVOCAP bite plates] Kцrber KH.Quintessenz. 1987 Sep;3 8(9):1553-62.

\section{Address for correspondence: \\ Metodi Abadzhiev \\ Prosthodontic Department, Faculty of Dental Medicine, \\ Medical University - Varna \\ 63, G.S.Rakovski Str., 9000 Varna, Bulgaria \\ E-mail: mabadjieff@yahoo.com}

